\title{
Effect of Light Simplified Cultivation Mode on Growth and Yield of Rice under Straw Returning Condition
}

\author{
Baifeng Cang ${ }^{1}$, Hao Jiang ${ }^{1}$, Rong $\mathrm{Ma}^{1}$, Yunzhe $\mathrm{Li}^{1}$, Jingjing Cui ${ }^{1}$, and Zhihai $\mathrm{Wu}^{1}{ }^{1, *}$ \\ ${ }^{1}$ Agronomy College, Jilin Agricultural University, Changchun 130118, Jilin, China
}

\begin{abstract}
In order to study the application of light and simplified cultivation mode in straw returning field. In the experiment, two treatments of straw returning and non-straw returning were used under the light simplified cultivation mode, and the differences of tiller number, dry matter accumulation, leaf area index, chlorophyll and yield were studied. Field cultivation experiments were carried out with Jihong 9 and Jinongda 138. The results showed that the yields of Jihong 9 and Jinongda138 straw returning to the field under the light and simplified cultivation mode were $2.00 \%$ and $3.63 \%$ higher than those under the non-straw returning mode. The total grain number in the yield components increased by $3.35 \%$ and $11.60 \%$ respectively. Dry matter increased by $19.70 \%$ and $7.66 \%$ in mature period. The leaf area index (LAI) and SPAD value in the later period of straw returning were higher than those in the non-straw returning, and the number of effective tillers was lower. Light and simplified cultivation can be used as a new mode of rice high-yield cultivation under straw returning, which improves the total grain number, leaf area index, SPAD value and dry matter in the later stage, and increases rice yield. The yield advantage of Jinongda 138 under straw returning (SJ138) is more significant.
\end{abstract}

\section{Introduction}

With the continuous improvement of China's agricultural comprehensive production level, China's agricultural production of straw continues to increase. According to statistics, China's annual straw production has become one of the largest countries in the world, but the straw utilization rate is less than $50 \%[1]$. Crop straw is a kind of carbon rich energy material, which can improve the nitrogen use efficiency of crops, loosen the soil, improve the permeability, so as to improve the nutrient absorption capacity of crops[2,3]. Therefore, straw returning is of great significance to the sustainable development of agriculture and the improvement of environment[4]. In the early stage of rice straw returning, rice growth was inhibited, but it had a positive impact on rice dry matter accumulation and other growth indicators in the middle and late stage of rice[5]. Therefore, straw returning combined with

"corresponding author: wuzhihai1116@163.com 
chemical fertilizer is one of the effective measures to improve soil fertility, improve ecological environment of rice fields and promote sustainable agricultural production[6].

\section{Materials and methods}

\subsection{Experiment design}

Jinongda138 and Jihong 9 were tested. Jinongda138 was artificially crossed with Jijing 83 as female parent and 158 as male parent. The growth period was 143 days, the plant type was compact and the tillering ability was strong. Jihong 9 was bred by pedigree method with Jijing 88 as female parent and Shennong 89366 as male parent. Its growth period was 142 days, plant type was compact and tillering ability was strong. Field cultivation experiment was carried out in Shulan City, Jilin Province in 2019 (43⒌ $\left.51^{\prime} \mathrm{N} 126^{\circ} 24^{\prime} \mathrm{E}\right)$. Shulan city belongs to temperate continental monsoon climate, with an average annual temperature of 4.3 degrees Celsius, an average annual rainfall of $683 \mathrm{~mm}$, an annual frost free period of 140 days, and the previous crop is rice. The seedlings will be raised on April 15, 2019, transplanted on May 22, and harvested on September 25. The leaf age of rice is 4 leaves and 1 heart, and 6 plants per hole.

Table 1. Fertilizer application rate under different treatments.

\begin{tabular}{|c|c|c|c|}
\hline Treatment & Cultivar & Density & Fertilization period \\
\hline \multirow{2}{*}{$\begin{array}{c}\text { Non-straw } \\
\text { returning }\end{array}$} & J9 & \multirow[t]{2}{*}{$30 \mathrm{~cm} * 13.33 \mathrm{~cm}$} & \multirow{2}{*}{$\begin{array}{l}\text { Fertilizer application rate: N-P-K=150-90-105 } \\
\text { Basal fertilizer: compound fertilizer }(20-12-14) 450 \mathrm{~kg} / \mathrm{hm}^{2} \\
\text { Tillering fertilizer: compound fertilizer } 225 \mathrm{~kg} / \mathrm{hm}^{2} \\
\text { Panicle fertilizer: compound fertilizer } 75 \mathrm{~kg} / \mathrm{hm}^{2}\end{array}$} \\
\hline & $\mathrm{J} 138$ & & \\
\hline \multirow{2}{*}{$\begin{array}{c}\text { straw } \\
\text { returning }\end{array}$} & SJ9 & \multirow[t]{2}{*}{$30 \mathrm{~cm}^{*} 13.33 \mathrm{~cm}$} & $\begin{array}{l}\text { Fertilizer application rate: N-P-K=150-90-105 } \\
\text { Tillage: urea75kg/hm } \\
\text { Basal fertilizer: compound fertilizer }(20-12-14) 276 \mathrm{~kg} / \mathrm{hm}^{2} \text {, } \\
\text { superphosphate } 116 \mathrm{~kg} / \mathrm{hm}^{2}\end{array}$ \\
\hline & SJ138 & & $\begin{array}{l}\text { Tillering fertilizer: compound fertilizer } 225 \mathrm{~kg} / \mathrm{hm}^{2} \\
\text { Panicle fertilizer: compound fertilizer } 75 \mathrm{~kg} / \mathrm{hm}^{2} \text { 、 potassium } \\
\text { chloride } 40 \mathrm{~kg} / \mathrm{hm}^{2} \text { 。 }\end{array}$ \\
\hline
\end{tabular}

In this experiment, two modes of straw returning and non-straw returning under the light and simplified cultivation mode were set. Jihong 9 and Jinongda 138 were tested. There are 4 treatments (specific treatments are shown in Table 1), namely, non-straw returning to field Jihong 9 (J9) and JNongda 138 (J138) under the light simplified cultivation mode, straw returning to field Jihong 9 (SJ9) and JNongda 138 (SJ138) under the light simplified cultivation mode. When the rice straw was decomposed, $300 \mathrm{~kg} / \mathrm{HA}$ was returned to the field, $75 \mathrm{~kg}$ urea and $30 \mathrm{~kg}$ effective microorganisms were added at the same time. Each plot is isolated by pond ridge to realize single row and single irrigation.

\section{2 Sampling and measurements}

\subsubsection{Dry matter}

At the jointing stage, panicle initiation stage, heading stage, filling stage and maturity stage, 
three representative plants (except the side row) with uniform growth were selected from each plot. The leaf area was measured by specific gravity method. The roots were removed, and the stems, leaves and panicles were packed separately. The green was killed at $105^{\circ} \mathrm{C}$ for $30 \mathrm{~min}$, and then dried at $80^{\circ} \mathrm{Cto}$ constant weight. Measure the weight of dry matter with a one in ten thousandth electronic balance.

\subsubsection{Tillering}

Ten representative holes with the same growth trend were selected in each plot, and the tiller was investigated and recorded in the jointing stage, panicle initiation stage, heading stage, filling stage and maturity stage of rice.

\subsubsection{SPAD value}

SPAD-502 chlorophyll meter (Minolta, Japan) was used to measure SPAD value of rice leaves at tillering stage, jointing stage, panicle initiation stage, heading stage and filling stage.

\subsubsection{Yield and its composition}

The number of effective spikes per hill with a representative area of $1 \mathrm{~m} 2$ was measured in the field at the mature stage. The 5-hole plants with the same average panicle number were selected for seed test after air drying. The number of grains per panicle, seed setting rate and 1000 grain weight were investigated. After threshing, impurity removal and sun drying, they were weighed.

\subsection{Data calculation and statistical analysis}

Leaf area index $(\mathrm{LAI})=0.75 \times \mathrm{S} 1(\mathrm{G} 1+\mathrm{G} 2) /(\mathrm{G} 1 \times \mathrm{S} 2)$. S1 is the sum of the leaf length multiplied by the width of three medium stem plants, G1 is the dry matter mass of the leaves of three medium stems, G2 is the dry weight of the remaining three clusters of leaves, $\mathrm{S} 2$ is the floor area of three clusters of rice, and 0.75 is the coefficient.

All the data were processed by Excel 2019 software to draw tables, SigmaPlot 12.5 to draw graphs, and spss24.0 to analyze analysis of variance (ANOVA).

Table 2. Effect of different treatments on rice yield and yield components.

\begin{tabular}{|c|c|c|c|c|c|}
\hline Treatment & $\begin{array}{c}\text { Panicle } \\
/\left(\mathrm{m}^{2}\right)\end{array}$ & Total grain number & $\begin{array}{c}\text { Seed-setting } \\
\text { rate/ }(\%)\end{array}$ & $\begin{array}{c}1000 \text {-grain } \\
\text { weight/ }(\mathrm{g})\end{array}$ & $\begin{array}{c}\text { grain yield } \\
/\left(\mathrm{kg} \cdot \mathrm{hm}^{-2}\right)\end{array}$ \\
\hline $\mathrm{J} 9$ & $\begin{array}{c}384.75 \pm \\
20.25 \mathrm{a}\end{array}$ & $118.12 \pm 7.89 \mathrm{c}$ & $89.28 \pm 2.53 \mathrm{a}$ & $21.63 \pm 0.41 \mathrm{a}$ & $\begin{array}{c}8757.46 \pm \\
476.62 \mathrm{~b}\end{array}$ \\
\hline $\mathrm{J} 138$ & $\begin{array}{c}377.00 \pm \\
12.56 \mathrm{a}\end{array}$ & $139.00 \pm 8.67 \mathrm{~b}$ & $81.88 \pm 2.20 \mathrm{~b}$ & $21.66 \pm 0.42 \mathrm{a}$ & $\begin{array}{c}9279.84 \pm \\
319.88 \mathrm{ab}\end{array}$ \\
\hline $\mathrm{SJ} 9$ & $\begin{array}{c}375.42 \pm \\
21.27 \mathrm{a}\end{array}$ & $122.08 \pm 1.75 \mathrm{c}$ & $91.21 \pm 2.03 \mathrm{a}$ & $21.04 \pm 0.63 \mathrm{a}$ & $\begin{array}{c}8932.45 \pm \\
375.95 \mathrm{ab}\end{array}$ \\
\hline SJ138 & $\begin{array}{c}368.33 \pm \\
12.27 \mathrm{a}\end{array}$ & $155.12 \pm 0.89 \mathrm{a}$ & $81.26 \pm 0.81 \mathrm{~b}$ & $20.73 \pm 0.86 \mathrm{a}$ & $\begin{array}{c}9616.75 \pm \\
237.58 \mathrm{a}\end{array}$ \\
\hline
\end{tabular}


Under the light simplified cultivation mode, the yield of straw returning to field was higher than that of non-straw returning treatment (Table 2). Compared with J9, the yield of sj9 increased by $2.00 \%$, and the yield of sj 138 increased by $3.63 \%$ compared with that of $\mathrm{J} 138$. The main reason was that the total number of cases of sj9 and sj 138 increased by $3.35 \%$ and $11.60 \%$ compared with $\mathrm{J} 9$ and $\mathrm{J} 138$; compared with sj9, the seed-setting rate of sj138 decreased by $10.91 \%$, but the total number of grains increased significantly by $27.06 \%$. The other yield components had no significant difference, and the yield was the highest.

The number of tillers increased from jointing stage to full heading stage, and remained stable after full heading stage (Table 3). At the jointing stage, the tiller number of J138 was significantly different from that of sj138; at the panicle initiation stage, the tiller number of J9 was significantly different from that of $\mathrm{sj}-9$, but there was no significant difference in the other three stages. In the whole growth period of rice, the tiller number of non-straw returning was more than that of straw returning under light simplified cultivation mode.

Table 3. Effect of different treatments on tillering.

\begin{tabular}{|c|c|c|c|c|c|}
\hline \multirow{2}{*}{ Treatment } & \multicolumn{5}{|c|}{ No. of stems andtillers } \\
\cline { 2 - 6 } & Jointing & Panicle initiation & Heading & Filling & Maturity \\
\hline J9 & $19.71 \pm 2.69 \mathrm{a}$ & $28.57 \pm 4.83 \mathrm{a}$ & $21 \pm 4.69 \mathrm{a}$ & $21.43 \pm 3.99 \mathrm{a}$ & $22.71 \pm 2.50 \mathrm{a}$ \\
\hline J138 & $19.29 \pm 3.09 \mathrm{a}$ & $26.71 \pm 4.15 \mathrm{ab}$ & $21.57 \pm 4.39 \mathrm{a}$ & $21.86 \pm 5.18 \mathrm{a}$ & $21.43 \pm 4.31 \mathrm{a}$ \\
\hline SJ9 & $20.14 \pm 3.85 \mathrm{a}$ & $23 \pm 3.74 \mathrm{~b}$ & $20 \pm 4 \mathrm{a}$ & $20.14 \pm 4.38 \mathrm{a}$ & $20.43 \pm 4.31 \mathrm{a}$ \\
\hline SJ138 & $15.86 \pm 2.04 \mathrm{~b}$ & $23.57 \pm 3.51 \mathrm{~b}$ & $20.14 \pm 2.79 \mathrm{a}$ & $20.57 \pm 4.89 \mathrm{a}$ & $21.14 \pm 4.14 \mathrm{a}$ \\
\hline
\end{tabular}

Table 4. Effect of different treatments on dry matter weight at different growth periods of rice.

\begin{tabular}{|c|c|c|c|c|c|}
\hline 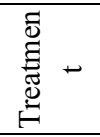 & $\begin{array}{l}\text { Jointing/ } \\
\left(\mathrm{t} \cdot \mathrm{hm}^{-2}\right)\end{array}$ & $\begin{array}{l}\text { Panicle } \\
\text { initiatio/ } \\
\left(\mathrm{t} \cdot \mathrm{hm}^{-2}\right)\end{array}$ & $\begin{array}{l}\text { Heading/ } \\
\left(\mathrm{t} \cdot \mathrm{hm}^{-2}\right)\end{array}$ & $\begin{array}{l}\text { Filling / } \\
\left(\mathrm{t} \cdot \mathrm{hm}^{-2}\right)\end{array}$ & $\begin{array}{c}\text { Maturity / } \\
\left(\mathrm{t} \cdot \mathrm{hm}^{-2}\right)\end{array}$ \\
\hline J9 & $2.44 \pm 0.48 b$ & 8.36 士 $0.71 \mathrm{a}$ & $12.07 \pm 0.63 b$ & $13.66 \pm 1.44 b$ & $14.21 \pm 1.70 \mathrm{~b}$ \\
\hline $\mathrm{J} 138$ & $3.30 \pm 0.56 \mathrm{a}$ & $9.74 \pm 0.87 \mathrm{a}$ & $14.34 \pm 0.50 \mathrm{a}$ & $15.91 \pm 029 a$ & $16.57 \pm 0.79 \mathrm{ab}$ \\
\hline SJ9 & $2.04 \pm 0.19 b$ & 7.22 士 $1.49 \mathrm{a}$ & $13.60 \pm 0.53 a$ & $14.20 \pm 0.77 \mathrm{ab}$ & $17.01 \pm 1.68 \mathrm{a}$ \\
\hline SJ138 & $2.03 \pm 0.23 b$ & $8.96 \pm 1.75 \mathrm{a}$ & $14.41 \pm 1.21 \mathrm{a}$ & $15.51 \pm 1.38 \mathrm{ab}$ & $17.84 \pm 0.64 \mathrm{a}$ \\
\hline
\end{tabular}

The accumulation of above ground dry matter increased gradually during the growth period of rice (Table 4). Under the light simplified cultivation mode at jointing stage panicle initiation stage, the dry matter weight of rice without straw returning was higher than that of straw returning, and the results were opposite at heading stage and mature stage. There was significant difference between J138 and SJ138, with an increase of $62.56 \%$ at jointing stage. There was no significant difference at panicle initiation stage. SJ9 and J9 reached significant difference, increased by $12.68 \%$ at heading stage. There was no significant difference among different treatments of the same variety at filling stage. SJ9 and J9 reached significant difference, increased by $19.70 \%$ at mature stage.

The dry matter accumulation of the same cultivar was significantly different under different treatments, and the proportion of dry matter in jointing stage to panicle initiation stage and panicle initiation stage to heading stage was the highest (Table 5). The dry matter accumulation of J138 reached the maximum at sowing stage to jointing stage, J9 at jointing young spike stage, sj9 at jointing stage to panicle initiation stage, S9 at heading stage to filling stage and sj9 at filling stage to mature stage. 
Table 5. Effect of different treatments on dry matteraccumulation and its proportion at different growth periods.

\begin{tabular}{|c|c|c|c|c|c|c|c|c|c|c|}
\hline \multirow[b]{2}{*}{ 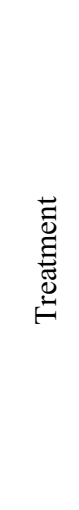 } & \multicolumn{2}{|c|}{$\begin{array}{c}\text { Sowing-Tillerin } \\
\mathrm{g}\end{array}$} & \multicolumn{2}{|c|}{$\begin{array}{l}\text { Tillering-Panicle } \\
\text { initiation }\end{array}$} & \multicolumn{2}{|c|}{$\begin{array}{c}\text { Panicle } \\
\text { initiation-Hea } \\
\text { ding }\end{array}$} & \multicolumn{3}{|c|}{ Heading-Filling } & \multirow{2}{*}{ 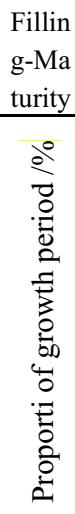 } \\
\hline & 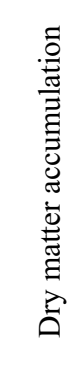 & 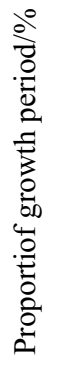 & 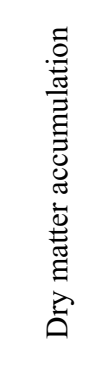 & 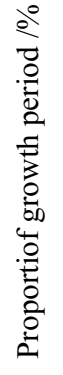 & 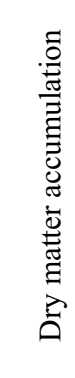 & 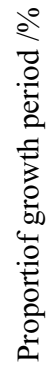 & 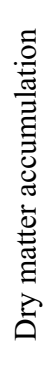 & 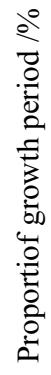 & 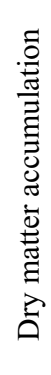 & \\
\hline J9 & 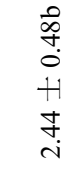 & $\frac{5}{0}$ & $\begin{array}{l}\text { o̊ } \\
\vdots \\
\dot{H} \\
\dot{\sigma} \\
\text { in }\end{array}$ & $\stackrel{\text { Tे }}{\circ}$ & 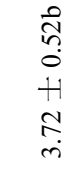 & ָ̊. & 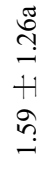 & $\overline{0}$ & $\begin{array}{l}0 \\
n \\
0 \\
0 \\
+1 \\
+ \\
n \\
0\end{array}$ & $\overbrace{0}$ \\
\hline $\mathrm{J} 138$ & 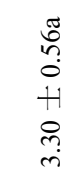 & กิ & \begin{tabular}{l}
$\stackrel{0}{2}$ \\
0 \\
+ \\
+1 \\
+ \\
\multirow{0}{0}{}
\end{tabular} & ले & $\begin{array}{l}\frac{\sigma}{\sigma} \\
\hat{a} \\
0 \\
+1 \\
\dot{0} \\
\dot{+}\end{array}$ & $\stackrel{\infty}{\sim}$ & $\begin{array}{l}\text { s. } \\
0 \\
0 \\
+1 \\
i n \\
i\end{array}$ & $\stackrel{\partial}{0}$ & $\begin{array}{l}0 \\
0 \\
0 \\
0 \\
+1 \\
n \\
0 \\
0\end{array}$ & 范 \\
\hline SJ9 & $\begin{array}{l}2 \\
\overrightarrow{0} \\
+1 \\
\dot{0} \\
\dot{i}\end{array}$ & $\frac{7}{0}$ & 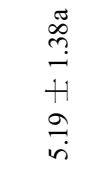 & ஸి & 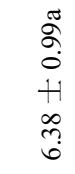 & $\hat{n}$ & $\begin{array}{l}\text { م̃ } \\
0 \\
+1 \\
0 \\
0 \\
0\end{array}$ & $\stackrel{+}{0}$ & 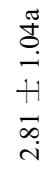 & $\frac{1}{0}$ \\
\hline SJ138 & $\begin{array}{l}0 \\
\text { तె } \\
0 \\
+1 \\
\text { ô } \\
\text { ì }\end{array}$ & $=$ & 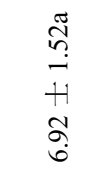 & है & 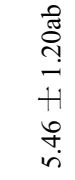 & $\overline{3}$ & 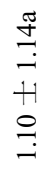 & $\stackrel{0}{\circ}$ & 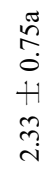 & 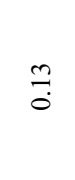 \\
\hline
\end{tabular}

Table 6. Effect of different treatments on leaf area index.

\begin{tabular}{|c|c|c|c|c|}
\hline \multirow{2}{*}{ Treatment } & \multicolumn{4}{|c|}{ Leaf area index } \\
\cline { 2 - 5 } & Jointing & Panicle initiation & Heading & Filling \\
\hline $\mathrm{J} 9$ & $\begin{array}{c}2.69 \pm 0.51 \\
\mathrm{a}\end{array}$ & $4.86 \pm 0.35 \mathrm{~b}$ & $4.44 \pm 0.53 \mathrm{~b}$ & $3.45 \pm 0.35 \mathrm{~b}$ \\
\hline $\mathrm{J} 138$ & $\begin{array}{c}2.36 \pm 0.51 \\
\mathrm{ab}\end{array}$ & $5.15 \pm 0.7 \mathrm{~b}$ & $6.84 \pm 0.57 \mathrm{a}$ & $3.65 \pm 0.33 \mathrm{ab}$ \\
\hline $\mathrm{SJ} 9$ & $\begin{array}{c}2.14 \pm 0.77 \\
\mathrm{ab}\end{array}$ & $5.46 \pm 0.19 \mathrm{ab}$ & $6.36 \pm 0.35 \mathrm{a}$ & $3.78 \pm 0.22 \mathrm{ab}$ \\
\hline $\mathrm{SJ} 138$ & $1.77 \pm 0.12 \mathrm{~b}$ & $6.31 \pm 0.44 \mathrm{a}$ & $7.11 \pm 0.11 \mathrm{a}$ & $4.26 \pm 0.41 \mathrm{a}$ \\
\hline
\end{tabular}


The leaf area index increased first and then decreased with the extension of growth period (Table 6). Under the light and simplified cultivation mode, the leaf area index of straw returning was higher than that of non-straw returning. There was no significant difference between different treatments of the same variety at jointing stage and filling stage. The leaf area index of SJ138 increased by $22.52 \%$ compared with that of J138 at panicle initiation stage, which reached a significant difference. At heading stage, leaf area index of sj9 and J9 increased by $43.24 \%$, reaching a significant difference.

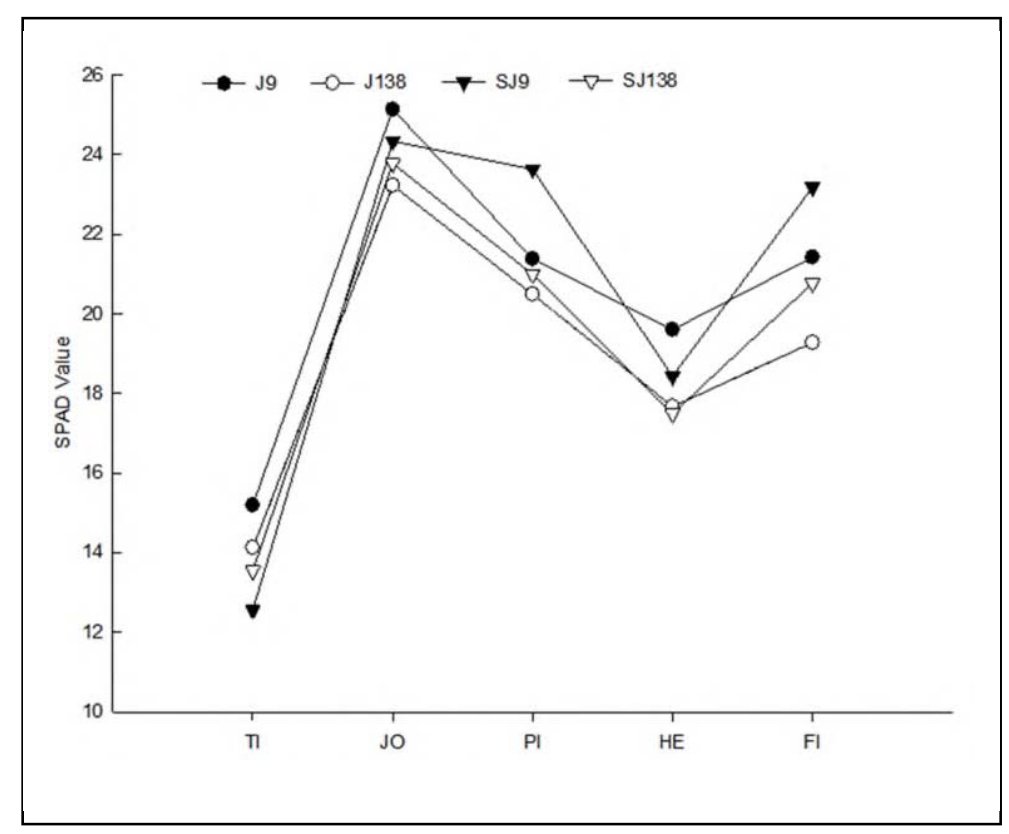

Fig. 1. SPAD values of different treatments.

The SPAD values of the four treatments were consistent, and increased first, then decreased and then increased with the growth period, and reached the maximum value at the jointing stage (Fig. 1). The SPAD value of J9 was higher than that of other treatments at tillering stage, jointing stage and heading stage. The SPAD value of sj9 was higher than that of other treatments at the stage of panicle initiation stage and filling stage.

\section{Discussion}

\subsection{Effects of straw returning on rice yield and its components}

Rice yield is composed of the number of effective ears per unit area, grain number, seed setting rate and 1000 grain weight. Straw returning can reduce the number of effective panicles of rice and increase the grain number ${ }^{[7]}$, which may be due to the decomposition of straw in the early stage, fixing part of nitrogen, hindering the early development of rice ${ }^{[8]}$, resulting in the reduction of effective panicles, while at the later stage, the grain number increased by releasing nutrients through decomposition of straw. Some studies have shown that straw returning significantly improves the seed setting rate and 1000 grain weight of rice ${ }^{[9]}$, but it is not reflected in this experiment, which may be related to the period when 
the external environment affects the decomposition rate of straw and leads to the release of nutrients.

\subsection{Effects of straw returning on rice growth and development}

Straw returning to the field inhibited the growth and development of rice at the early stage and promoted the growth and development of rice at the late stage $\mathrm{e}^{[10][11]}$. In the early stage of straw returning, the dry matter quality of rice was lower than that of non-straw returning, and the dry matter quality of rice after straw returning was higher than that of non-straw returning. At the same time, straw returning reduced the number of tillers in the early stage of rice ${ }^{[12]}$, which led to the reduction of panicles per square meter of non-straw returning rice than that of straw returning. Compared with non-straw returning management, straw returning reduced leaf area index (LAI) and chlorophyll content (SPAD value) in the early stage, but there was no significant difference at heading and after stage ${ }^{[13]}$, but increased.

\section{Conclusions}

Straw returning and non-straw returning have significant effects on the growth and yield of rice under light simplified cultivation mode, which can be used as a technical mode for increasing yield and increasing economic benefits. In this experiment, the early growth and development of rice was hindered under straw returning. With the release of nutrients from straw decomposition, grain number, dry matter accumulation in the late growth stage, leaf area index and SPAD value increased, and the yield of Jihong 9 and Jinongda 138 was increased. The yield advantage of jinongda138 was more obvious.

This work was supported by the National Key Research and Development Project (2018YFD0300207,2017YFD0300609) , and the Jilin Province Science and Technology Development Plan Project (20190301061NY,20200403016SF).

\section{References}

1. HE Hu, WU Jian Fu,ZENG Yan Hua et al,Effects of Nitrogen Management on Yield and Nitrogen Utilization of Double Cropping Late Rice under Total Tice Straw Incorporation, Journal of Plant Nutrition and Fertilizer, 20(04),811-820 (2014)

2. Guanghuo Wang, Achim Dobermann, Christian Witt, et al. Performance of SiteSpecific Nutrient Management for Irrigated Rice in Southeast China, Agronomy Journal, 93(4),869-878 (2001)

3. WANG Xuan De, SHI Xiao Jun, SONG Guang Yu. Effects of Long-term Rice Straw Returning on the Fertility and Productivity of Purplish Paddy Soil, Plant Nutrition and Fertilizing Science, 03,302-307 (2005)

4. PENG Yao Lin, ZHU Jun Ying, TANG Jian Jun et al. Effects of Long-term Mixed Application of Organic-inorganic Fertilizers on the Yield and Dry Matter Produing Characters of Rice, Acta Agriculturae Universitis Jiangxiensis, 04,485-490 (2004) 
5. LI Feng Bo, NIU Yong Zhi, GAO Wen Ling et al. Effects of Tillage Styles and Straw Return on Soil Properties and Crop Yields in Direct Seeding Rice, Chinese Journal of Soil Science, 2008(03), 549-552 (2008)

6. TANG Hai Ming, XIAO Xiao Ping, TANG Wen Guang et al. Effects of Covering Paddy Field by Crop Straw in Winter on Nutrition Accumulation and Translocation of Rice Plant, Journal of Agricultural Science and Technology, 20(08),63-73 (2018)

7. LIU Shi Ping,NIE Xin Tao,ZHANG Hong Cheng et al. Effects of Tillage and Straw Returning on Soil Fertility and Grain Yield in a Wheat-rice Double Cropping System, Transactions of the Chinese Society of Agricultural Engineering, 07,48-51 (2006)

8. FU Ming Ying, ZHU Li Qun, LI Yan et al. Effects of Straw Deep-buried on Rice Growth and Yield, Jiangsu Agricultural Sciences, 41(01),67-69 (2013)

9. TANG Yin Sheng. Effects of Straw Returning on Machine-Transplanted japonica Rice Characteristics and Yield Components, Anhui Agricultural Science Bulletin, 18(04), 57-58 (2012)

10. MA Chun Mei, WANG Yong Ji, YU Shu Han et al, Effects of rice straw returning and nitrogen application on nitrogen uptake and yield of rice, Journal of Northeast Agricultural University, 48(06),9-16 (2017)

11. PEI Peng Gang. Effects of Straw Incorporation Coupled Nitrogen levels on Biochemical Properties of Paddy Soil and Growth Characteristics of Rice, Chinese Academy of Agricultural Sciences (2014)

12. LI Chao Su, XIE Rui Zhi, HUANG Gang et al. Effects of nitrogen management on rice growth and grain yield under conservation tillage in rice-wheat cropping system, Plant Nutrition and Fertilizer Science, 16(03),528-535 (2014)

13. XU Guo Wei. Effects of Planting Patterns, Straw Application and Sit-specific Nitrogen Management on Grain Yield and Quality of Rice and Their Physiological Mechanism. Yangzhou University 